\title{
Integrasi Model SWAT dan SIG dalam Upaya Menekan Laju Erosi DAD Deli, Sumatera Utara
}

\author{
Riki Rahmad ${ }^{1}$, Ali Nurman ${ }^{2}$ dan Mona Adria Wirda ${ }^{3}$
}

Jurusan Pendidikan Geografi Fakultas Ilmu Sosial Universitas Negeri Medan, Sumatera Utara, Indonesia ${ }^{1,2.3}$

Email Koresponden:rikirahmad@unimed.ac.id

Diterima: 15 September 2016/Disetujui: 08 Februari 2017/ Publikasi online:: 31 Maret 2017

() 2017 Fakultas Geografi UGM dan Ikatan Geograf Indonesia (IGI)

\begin{abstract}
Abstrak Penelitian ini bertujuan untuk melakukan simulasi model SWAT dalam menghitung besarnya laju erosi DAS, menguji kesesuaian model dalam memprediksi erosi, serta menentukan skenario penggunaan lahan yang paling optimal menurunkan laju erosi. Penelitian ini dilakukan di DAS Deli, Sumatera Utara. Pada penelitian ini analisis SWAT dilakukan dengan bantuan Sistem Informasi Geografi (SIG) melalui 4 proses yaitu delineasi, pembentukan Hydrological Response Unit (HRU), pengolahan data dan simulasi, serta proses visualisasi. Hasil penelitian menunjukkan besarnya erosi rata-rata DAS Deli adalah 410,72 ton/ha/tahun. Hasil ini menunjukkan DAS Deli termasuk kedalam Tingkat Bahaya Erosi (TBE) kategori Berat dengan kriteria sangat berat 37,04\%, berat $17,07 \%$, sedang $21,46 \%$, ringan $17,38 \%$, dan sangat ringan 7,04\%. Uji validasi model menunjukkan bahwa ada hubungan positif antara debit model dan observasi dimana persentase perbedaan nilainya sangat kecil yang artinya besarnya debit model hampir sangat mendekati besarnya debit observasi, serta model dikategorikan sangat baik dalam melakukan simulasi debit aliran harian pada Sungai Deli. Metode skenario adalah berdasarkan analisis TBE. Hasil skenario penggunaan lahan berhasil menurunkan laju erosi DAS Deli $34,78 \%$ menjadi 267,88 ton/ha/tahun.
\end{abstract}

\section{Kata kunci: Daerah Aliran Sungai, SWAT, SIG, erosi, lahan}

\begin{abstract}
This study aims to conduct SWAT model simulation calculation of the rate of erosion of the watershed, testing the suitability of the model in predicting erosion, land use scenarios and determine the most optimal decrease the rate of erosion. This research was conducted in the watershed Deli, North Sumatra. In this study, SWAT analysis performed with the help of Geographical Information Systems (GIS) through 4 delineation process, namely, the establishment of Hydrological Response Unit (HRU), data processing and simulation, as well as the visualization process. The results show the average amount of erosion DAS Deli is 410.72 ton/ha/year. These results indicate DAS Deli included into Erosion Hazard Level (TBE) weight category with very strict criteria $37.04 \%, 17.07 \%$ by weight, were $21.46 \%, 17.38 \%$ mild and very mild $7.04 \%$. Test model validation indicates that there is a positive relationship between the discharge and observation models where the percentage difference in value is very small, which means the amount of discharge model is very very close to a number of discharge observations, and models are categorized very good at simulating the daily flow rate at the Deli River. The scenario method is based on analysis of TBE. The results of land use scenarios managed to reduce the rate of erosion of the watershed Deli $34.78 \%$ to 267.88 tons/ha/year.
\end{abstract}

Keywords: Watershed, SWAT, GIS, erosion, land

\section{PENDAHULUAN}

Erosi merupakan salah satu permasalahan lingkungan yang sangat serius pada suatu ekosistem Daerah Aliran Sungai (DAS). Erosi adalah peristiwa terlepasnya partikel-partikel tanah dari permukaan yang mengakibatkan ikut hilangnya material, nutrisi organik tanah, penurunan produktivitas panen dan penurunan kualitas air. Fenomena tersebut dapat disebabkan oleh kerusakan ekosistem di sepanjang DAS terutama berkurangnya luas hutan. Penurunan luas vegetasi merupakan masalah serius pada ekosistem Daerah Aliran Sungai (DAS). Tutupan lahan berupa vegetasi berfungsi sebagai pertahanan DAS terhadap proses erosi (Mechram, 2011).

Pengelolaan Daerah Aliran Sungai (DAS) merupakan kegiatan memperbaiki, memelihara, dan melindungi keadaan DAS, agar dapat menghasilkan barang dan jasa khususnya, baik kuantitas, kualitas, maupun kontinuitas air. Keberhasilan pengelolaan DAS diindikasikan dengan fluktuasi debit, beban sedimen sungai, serta kelestarian sumber-sumber air. Indikator lain yang juga cukup penting adalah erosi tanah (Nursidah, 2012).

Menurut Miardini, dkk (2016), salah satu tujuan dari pengelolaan DAS adalah untuk mengendalikan banjir dan mengatur hasil air baik dari segi kuantitas, kualitas, maupun dari segi kontinuitas. Dalam memahami dan melaksanakan pengelolaan DAS harus dilihat secara holistik. Pengelolaan yang diharapkan adalah pengelolaan yang mamapu mengakomodasi seluruh kepentingan, yaitu ekologis, ekonomis, dan sosial budaya. Pengelolaan DAS merupakan proses pengarahan dan pengorganisasian penggunaan lahan dan sumberdaya lainnya pada suatu DAS untuk menyediakan barang dan jasa yang diinginkan tanpa merusak sumberdaya tanah dan air (Lestari, 2010). 
Penyusunan rencana pengelolaan DAS memerlukan data dasar di antaranya adalah erosi dan sedimentasi. Salah satu metode yang pertama kali dikembangkan untuk memprediksi erosi adalah metode USLE (Universal Soil Loss Equation) yang merupakan metode empiris. Metode USLE memiliki beberapa kelemahan antara lain hanya memperkirakan besar kehilangan tanah rata-rata tahunan dan hanya memperkirakan erosi lembar dan alur, tidak memperhitungkan endapan sedimen dan hanya sesuai untuk gradient kemiringan 3-20\% sehingga tidak mewakili proses erosi yang sebenarnya (Asdak, 2004). Bertolak dari keterbatasanketerbatasan metode USLE maka parameter yang digunakan disesuaikan penggunaanya di Indonesia. Upaya yang dilakukan adalah memodifikasi metode USLE menjadi MUSLE (Modified Universal Soil Loss Equation).

Salah satu model yang cukup berkembang adalah pemodelan SWAT. Pemodelan berbasis physical-based ini sudah banyak dipakai di berbagai jenis dan kondisi DAS. Pemodelan SWAT dapat memprediksi pengaruh manajemen lahan pada limpasan air, sedimen, dan lahan pertanian dalam suatu hubungan yang kompleks pada suatu DAS termasuk di dalamnya jenis tanah, penggunaan lahan dan manajaemen kondisi lahan secara periodik. SWAT memakai rumus MUSLE untuk analisis erosi dan sedimentasi. Penggunaan model SWAT dapat mengidentifikasi, menilai, mengevaluasi tingkat permasalahan suatu DAS dan sabagai alat untuk memilih tindakan pengelolaan dalam mengendalikan permasalahan tersebut, sehingga diharapkan dengan penggunaan model SWAT dapat dikembangkan beberapa skenario guna menentukan kondisi perencanaan pengelolaan DAS terbaik (Junaidi, 2013).

Untuk penggunaan model SWAT di Indonesia, terlebih dahulu perlu dilakukan kalibrasi dan validasi sesuai dengan ketersediaan data, agar hasil yang diperoleh dapat sesuai dengan kondisi sebenarnya di lapangan. Proses ini dibutuhkan karena setiap DAS memiliki karakteristik yang berbeda-beda. Relevansi model dengan keadaan yang sebenarnya dievaluasi dengan memperhitungkan standar deviasi dan efisiensi model (Pandjaitan, 2015).

Kota Medan merupakan wilayah yang menarik untuk dianalisis untuk studi, ini dikarenakan Kota Medan dengan peruntukan lahan yang kompleks dilalui 3 Daerah Aliran Sungai (DAS) besar. Salah satunya yang melintasi langsung mulai dari hulu hingga hilir sungai adalah Daerah Aliran Sungai (DAS) Deli. Sungai Deli merupakan salah satu induk sungai pada Satuan Wilayah Sungai (SWS) Belawan/ Belumai Ular dengan 5 (lima) anak sungai. Panjang sungai sekitar $73 \mathrm{~km}$ dengan luas basin $402 \mathrm{~km}^{2}$. Sungai Deli beserta anak dan ranting sungainya mengalir dari Kabupaten Karo, Kabupaten Deli Serdang dan melintasi Kota Medan sebelum bermuara ke Selat Malaka. Bagian hulu sungai pada umumnya berada di Kabupaten Karo dan Kabupaten Deli Serdang, sedangkan bagian tengah dan hilir berada di Kota Medan. Sungai Deli merupakan penyumbang sumber air terbesar bagi penduduk kota Medan. Salah satu indikator yang dapat dijadikan ukuran dalam melihat baik buruknya DAS adalah jumlah debit air di sungai tersebut. Kondisi Sungai Deli saat ini dapat dikatakan sangat buruk. Semakin menurunnya debit air yang disediakan Sungai Deli menjadi bukti buruknya pengelolaan DAS Deli. Tak hanya soal debit, juga permasalahan kontinuitas, ketersediaan, dan kualitas juga menjadi ukuran penting yang harus dilihat.

Alih fungsi lahan yang terjadi di DAS Deli telah menyebabkan perubahan karakteristik hidrologi dan apabila tidak dilakukan perbaikan maka akan mengakibatkan hilangnya sumber air yang pontensial di masa yang akan datang. Oleh karena itu, perlu adanya suatu pengelolaan DAS yang baik yang dapat menjamin terjaganya distribusi air sepanjang tahun dan dapat meminimalkan terjadinya peningkatan aliran permukaan. Pengurangan daerah resapan air sebagai dampak perubahan fungsi lahan yang pada daerah hulu DAS Deli dapat menimbulkan dampak pada bagian DAS Deli lainnya baik bagian tengah maupun bagian hilir. Semakin berkurangnya lahan hijau sebagai daerah resapan air maka akan meningkatkan jumlah air yang tidak terserap tanah dan mengalir dipermukaan. Dampak pengurangan jumlah air yang terserap tanah ini salah satunya dapat terlihat dengan jelas adanya perubahan debit aliran sungai (runoff). Berkaitan dengan masalah-masalah tersebut maka diharapkan pemodelan erosi dengan menggunakan model SWAT dengan bantuan SIG ini dapat dijadikan dasar dalam perencanaan pengelolaan DAS Deli.

Tujuan dilakukannya penelitian ini adalah: (1) Melakukan simulasi model untuk mendapatkan besarnya erosi di DAS Deli; (2)Menguji kesesuaian model dalam memprediksi erosi di DAS Deli; (3) Menentukan skenario penggunaan lahan yang paling optimal dalam rangka menurunkan laju erosi di DAS Deli. Lokasi yang dipilih untuk melakukan pemodelan dilakukan pada DAS Deli. DAS (Daerah Aliran Sungai) Deli merupakan Daerah Aliran Sungai di Provinsi Sumatera Utara dengan luas 47,298.01 Ha. Daerah Aliran Sungai Deli terbentang antara $3^{\circ} 13^{\prime} 35,50^{\prime \prime} \mathrm{s} / \mathrm{d} 3^{\circ} 47^{\prime}$ 06,05” garis Lintang Utara dan meridian $98^{\circ} 29^{\prime} 22,52^{\prime \prime}$ s/d $98^{\circ} 42^{\prime}$ 51,23" Bujur Timur. Secara adminitrasi DAS Deli berada pada 3 (tiga) Kabupaten yaitu Kabupaten Karo seluas 1,417.65 Ha (3 \%), Kabupaten Deli Serdang seluas 29,115.20 Ha (61.56 \%) dan Kota Medan seluas $16,765.16$ ha $(35.45 \%)$. Pemilihan lokasi penelitian ini didasarkan pada ketersediaan data serta pertimbangan merupakan DAS prioritas yaitu DAS kritis yang memerlukan penanganan segera.

\section{METODE PENELITIAN}

Bahan yang digunakan dalam penelitian ini berupa data spasial dan data non-spasial. Data spasial yang digunakan meliputi data DEM (Digital Elevation 
Model) wilayah DAS Deli, peta batas DAS dan jaringan sungai DAS Deli, peta tataguna lahan DAS DAS Deli dan Peta jenis tanah DAS Deli.

Adapun data non-spasial yang digunakan meliputi data curah hujan harian selama 30 tahun terakhir dari stasiun penakar hujan yang ada di dalam maupun yang berada di sekitar DAS Deli, data klimatologi, meliputi data temperatur udara (maksimum dan minimum), kelembaban relatif udara, kecepatan angin dan radiasi sinar matahari, selama 10 tahun dari stasiun klimatologi yang ada di wilayah DAS Deli dan data karakteristik tanah yang ada di DAS Deli.

Alat yang digunakan terdiri dari perangkat keras (hardware) dan perangkat lunak (software).Perangkat keras (hardware), terdiri dari PC (Personal Computer), digunakan untuk membantu mempercepat proses pekerjaan penelitian secara umum.

Perangkat lunak (Software) Microsoft Office Word, Excel, dan Acces masing-masing digunakan untuk membantu pengolahan kata dan data numerik, ArcGIS 10.1, digunakan untuk pengolahan dan analisis data spasial dan SWAT Versi 09.93.3, digunakan untuk analisis pemodelan yang nantinya menghasilkan kajian erosi DAS Deli.

Tahap analisis dan pengolahan data menggunakan SWAT secara garis besar dapat dibagi kedalam beberapa kelompok tahapan yaitu deliniasi DAS, pendefinisian HRUs (Hydrologic Reponse Units), pendefinisian data iklim, menjalankan simulasi model dan Validasi model.

\section{HASIL DAN PEMBAHASAN}

Langkah pertama yang dilakukan dalam melakukan pemodelan pada ArcSWAT adalah deliniasi DAS. Model melakukan deliniasi DAS secara otomatis berdasarkan data DEM yang dimasukkan. Metode yang dilakukan dalam proses deliniasi DAS adalah dengan metode Treshold (ambang batas). Besar kecilnya threshold yang dimasukkan akan menentukan banyaknya jaringan sungai dan sub DAS yang akan dihasilkan kemudian.

Dari hasil delineasi DAS yang dilakukan untuk DAS Deli tidak sama persis dengan batas DAS dari BPDAS karena model masih kesulitan untuk mendeliniasi DAS di bagian hilir yang relatif datar. Tapi hasil yang dikeluarkan cukup memadai untuk dijadikan batasan dalam melakukan pemodelan. Hasil deliniasi dari DAS Deli dapat dilihat pada Tabel 1 dan Gambar 1.

Dari Tabel.1 dan Gambar.1 di atas didapatkan bahwa terdapat sedikit perbedaan antara luas dan jumlah sub-DAS antara BPDAS Wampu Sei Ular dengan luas dan jumlah sub-DAS dari luaran model SWAT, dimana BPDAS Wampu Sei Ular membagi 7 wilayah sub-DAS dengan luas total DAS adalah 47.299 Ha. Sedangkan model SWAT menghasilkan 102 subDAS dan luas total DAS adalah $40.788 \mathrm{Ha}$. Dilihat dari sebaran wilayah dapat terlihat bahwa model agak kesulitan untuk mendelineasi wilayah yang relatif datar yaitu yang berada di hilir DAS.

\section{Pembentukan HRUs (Hydrologic Response Units)}

HRUs merupakan unit analisis hidrologi yang

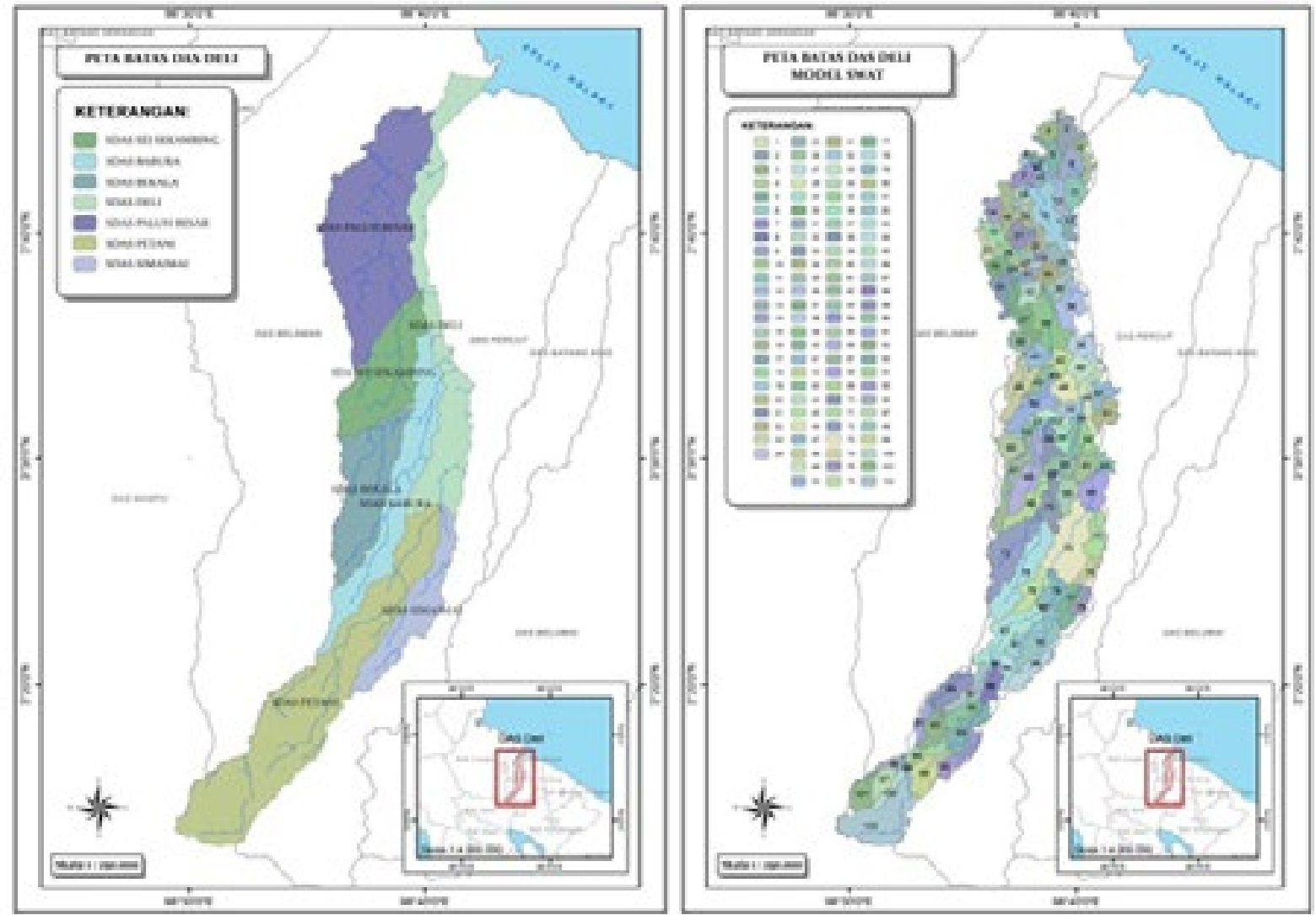

Gambar 1. Perbandingan Luas DAS Deli Dari BPDAS dan SWAT 
merupakan gabungan karakteristik dari penggunaan lahan, jenis tanah, dan kelerengan. Peta HRUs didapat dari tumpang susun peta penggunaan lahan, jenis tanah, dan peta lereng. Langkahnya adalah pemasukan peta penggunaan lahan dan jenis tanah, setelah itu mengklasifikasi ulang jenis penggunaan lahan dan jenis tanah sesuai database SWAT dan untuk peta lereng didapat dari DEM yang dibagi ke dalam lima kelas kelerengan. Setelah semua data dimasukkan dan diklasifikasi, langkah selanjutnya melakukan tumpang susun ketiga jenis peta sehingga muncul keluaran peta HRU.

HRUs yang terbentuk dari keluaran model dengan metode threshold by percentage (penggunaan lahan 10 $\%$, jenis tanah $10 \%$, lereng $10 \%$ ) untuk DAS Deli adalah sebanyak 1261 HRU.

\section{Pendefinisian Stasiun Hidroklimatologi}

Setelah unit analisis terbentuk, langkah selanjutnya adalah pemasukan data iklim. Basisdata iklim disimpan dalam tabel sesuai dengan format basis data SWAT. Masing-masing stasiun iklim memiliki data berupa curah hujan harian, temperatur udara, kecepatan angin, dan radiasi matahari.

DAS Deli mempunyai 3 stasiun iklim yang bersumber dari BMKG dengan time series dari tahun 1985 sampai 2015. Lokasi masing-masing stasiun iklim pada DAS Deli dapat dilihat pada Tabel 2.

\section{Menjalankan Model}

Setelah semua data dan koreksi telah dilakukan, langkah selanjutnya adalah eksekusi model untuk menghasilkan keluaran model terkait perhitungan erosi dan sedimentasi. Sebelum melakukan eksekusi ada

Tabel 1. Perbandingan Jumlah dan Luas DAS Deli

\begin{tabular}{lllc}
\hline \multicolumn{2}{c}{ BPDAS Wampu Sei Ular } & \multicolumn{2}{c}{ SWAT } \\
Sub DAS & Luas (Ha) & Sub DAS & Luas(Ha) \\
\hline Simaimai & 3.089 & & \\
Petani & 12.695 & & \\
Bekala & 4.426 & 102 Sub DAS & 40.788 \\
Babura & 5.180 & & \\
SeiSikambing & $4 . .224$ & & \\
Paluh Besar & 10.824 & & 40.788 \\
Deli & 6.861 & & \\
Jumlah & 47.299 & & \\
\hline Sumber: Hasil Pengolahan SIG, 2016
\end{tabular}

Tabel 2. Lokasi Stasiun Iklim DAS Deli

\begin{tabular}{llll}
\hline NAME & XPR & YPR & ELEVATION \\
\hline Sampali & 468332 & 399161 & 25 \\
Belawan & 468346 & 418726 & 3 \\
Tntngan & 451129 & 386982 & 86 \\
\hline
\end{tabular}

Sumber: BMKG, 2016

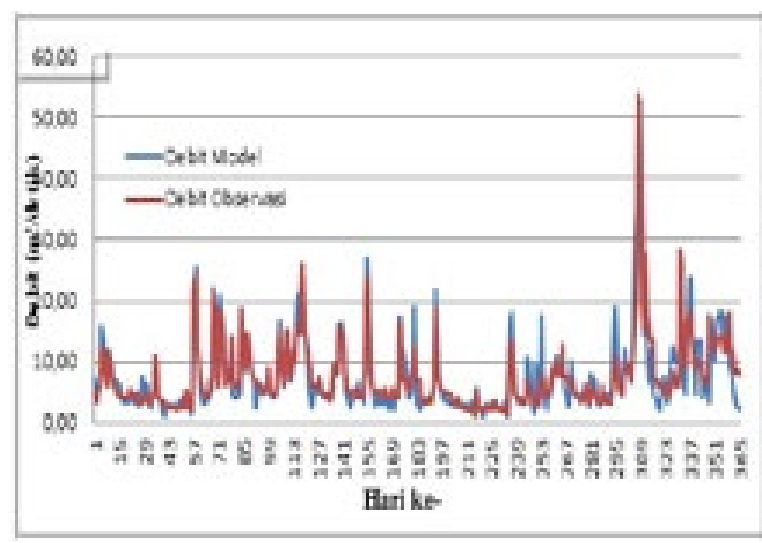

Gambar 2 . Validasi Debit Aliran Harian Sungai Deli Tahun 2015

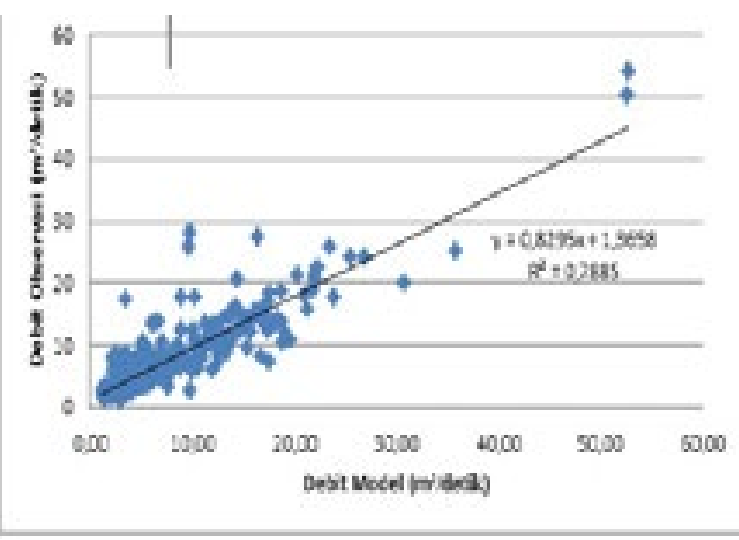

Gambar 3. Hubungan Antara Debit Aliran Harian Model dan Observasi Sungai Deli 


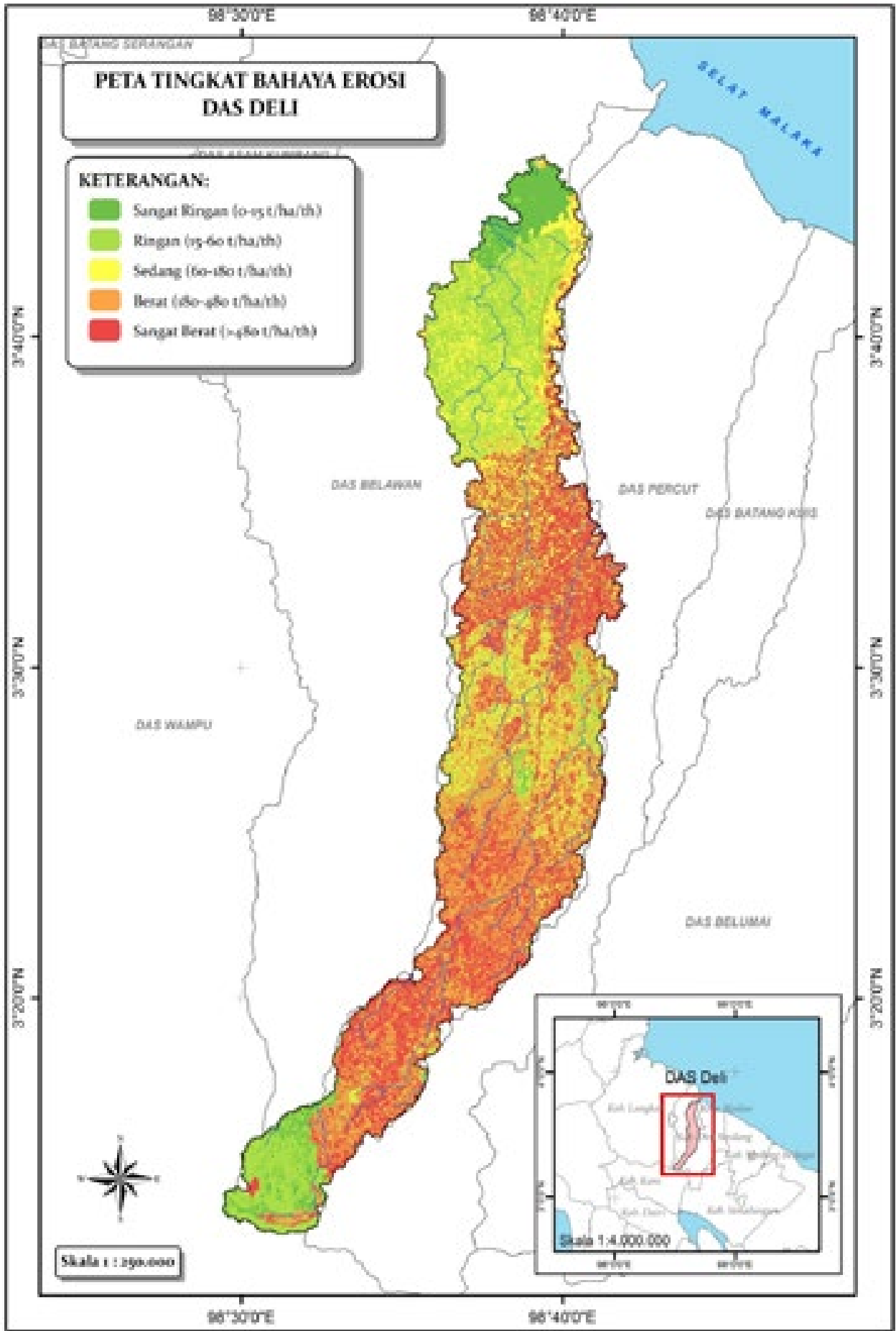

Gambar 4. Peta Tingkat Bahaya Erosi DAS Deli

beberapa pilihan dalam menentukan keluaran model, diantaranya metode distribusi curah hujan, jangka waktu simulasi, serta besaran output untuk jangka waktu harian, bulan, dan tahunan.

Untuk output SWAT pada DAS Deli dipilih metode distribusi skewed normal. Periode waktu simulasi sesuai dengan data iklim yaitu dari 1 Januari 1985 sampai dengan 31 Desember 2015, dan untuk jangka waktu simulasi dipilih tahunan untuk memudahkan dalam perhitungan total. Setelah model SWAT dieksekusi maka hasil output akan terangkum dalam file SWAT
Output Files yang terdiri dari file hru, sub, dan rch. File hru berisikan informasi keluaran untuk masing-masing HRU. File sub berisikan data keluaran pada masingmasing sub DAS, dan file rch berisikan data keluaran untuk sungai utama pada masing-masing sub DAS.

\section{Simulasi Model}

Perhitungan erosi yang dihasilkan dari running model SWAT adalah erosi untuk setiap HRU dan erosi untuk setiap sub DAS dengan periode waktu simulasi selama 30 tahun. Setelah semua parameter data telah 
dimasukkan, langkah selanjutnya adalah menjalankan program SWAT. Dari menu toolbar SWAT Simulation pilih Run SWAT maka akan keluar dialog box untuk menjalankan simulasi.

Pada menu ini terdapat beberapa pilihan dan pengaturan dalam menjalankan simulasi model seperti pengaturan hasil output harian, bulanan, dan tahunan sesuai pilihan pengguna. Setelah semua pengaturan sudah di set, langkah selanjutnya adalah Setup SWAT Run dan Run SWAT. Jendela DOS akan muncul yang menandakan program sedang melakukan proses simulasi. Pada tahap ini proses simulasi program SWAT telah berhasil dijalankan untuk selanjutnya membaca output file dari hasil simulasi pemodelan. Output SWAT tersimpan dalam file-file output (SWAT Output File) yang terdiri dari file BSB, SBS dan RCH. File BSB berisi informasi sub DAS, file SBS berisi informasi masing-masing HRU dan RCH berisi informasi pada masing-masing sungai utama dalam sub DAS.

Perhitungan Erosi DAS

Besarnya erosi pada setiap HRU pada DAS Deli adalah 0,43 ton/ha/tahun sampai dengan $4.272,54$ ton/ ha/tahun, dengan rata-rata sebesar 410,72 ton/ha/th. Erosi pada tingkat HRU terendah terdapat pada HRU 86 pada sub DAS 4 yaitu sebesar 0,43 ton/ha/th dengan penggunaan lahan tambak dan jenis tanah eutropeps serta lereng 0-8 \%, sedangkan erosi tertinggi sebesar 2.317,45 ton/ha/th terdapat pada HRU 1227 pada sub DAS 102 dengan penggunaan lahan lahan terbuka, jenis tanah dystrandepts, serta lereng $>45 \%$.

Besar erosi untuk skala DAS berkisar antara 2,27 ton/ha/th sampai dengan 5.420,6 ton/ha/th. Erosi terendah terdapat pada sub DAS 2 dan erosi tertinggi terdapat pada sub DAS 80 .

\section{Validasi Model}

Penggunaan model pada suatu DAS harus memperhatikan faktor validitasnya, hal ini disebabkan masing-masing DAS memiliki karakteristik yang berbeda. Validasi bertujuan agar keluaran model yang digunakan hasilnya mendekati keluaran dari DAS sebenarnya. Hal ini sangat diperlukan untuk menguji kesesuaian model dalam analisa hidrologi DAS.

Validasi untuk DAS Deli dilakukan pada satu outlet sesuai dengan data sekunder yang tersedia yaitu data debit aliran Sungai Deli diperoleh dari Balai Wilayah Sungai (BWS) Sumatera II Medan. Kriteria statistik yang digunakan dalam validasi model antara lain koefisien determinasi $\left(\mathrm{R}^{2}\right)$, persentase perbedaan dari nilai observasi (DVI), dan koefisien Nash-Sutcliffe (ENS).

Penelitian Yustika (2012) menyebutkan validasi debit harian bulan Februari dan Maret tahun 2009 dan 2011 menunjukkan R 0,88 dan NSE 0,74. Nilai kalibrasi ini menunjukkan bahwa model SWAT dapat digunakan untuk memprediksi kondisi hidrologi pada sub DAS Ciliwung Hulu.

Validasi untuk DAS Deli menggunakan data debit aliran pada tahun 2015. Outlet yang digunakan untuk kalibrasi pada model disesuaikan dengan lokasi SPAS Sungai Deli yaitu outlet pada sub DAS 1 yang terletak di bagian hilir Sungai Deli. Hasil validasi debit aliran harian pada Sungai Deli menunjukkan rata-rata debit aliran model dan observasi sebesar $7,48 \mathrm{~m}^{3} /$ detik dan $7,57 \mathrm{~m}^{3} /$ detik. Gambar menunjukkan koefisien determinasi $\left(\mathrm{R}^{2}\right)$ sebesar 0.79 , sedangkan perhitungan rata-rata nilai sebesar $-0,22 \%$, dan perhitungan untuk koefisien antara debit model dan observasi sebesar 0,75. Dari hasil $\mathrm{R}^{2}$, dan menunjukkan ada hubungan positif antara debit model dan observasi dimana persentase perbedaan nilainya sangat kecil yang artinya besarnya debit model hampir sangat mendekati besarnya debit observasi, serta model dikategorikan sangat baik dalam melakukan simulasi debit aliran harian pada Sungai Deli. Hasil validasi debit aliran harian pada Sungai Deli dapat dilihat pada Gambar 2 dan Gambar 3.

\section{Klasifikasi Tingkat Bahaya Erosi (TBE)}

Klasifikasi tingkat bahaya erosi diperoleh dengan membandingkan hasil hitungan total tanah yang tererosi per tahun pada masing-masing HRU dan Tingkat Bahaya Erosi (TBE) dapat dihitung dengan cara membandingkan laju erosi suatu lahan (land unit) terhadap besarnya erosi yang diperbolehkan.

Hasil erosi rata-rata DAS Deli menghasilkan angka sebesar 410,72 ton/ha/tahun, sedangkan hasil erosi untuk setiap unit lahan bervariasi mulai dari 0,43 ton/ha/tahun sampai dengan $4.272,54$ ton/ha/ tahun. Setelah besar erosi untuk setiap unit lahan HRU dihasilkan, langkah selanjutnya adalah membagi kelas erosi masing-masing unit lahan tersebut sesuai dengan ketentuan, yaitu berdasarkan kedalaman efektif tanah. Hasil Tingkat Bahaya Erosi (TBE) DAS Deli dapat dilihat pada Tabel 3 .

Tabel 3 menunjukkan bahwa Tingkat Bahaya Erosi (TBE) paling tinggi pada DAS Deli adalah tingkat Sangat Berat dengan luas lahan $15.107,82$ ha atau $37,04 \%$ dari total keseluruhan wilayah, disusul berikutnya kelas TBE Sedang dengan luas lahan $8.752,77$ ha atau $21,46 \%$ dari luas wilayah DAS. Tingkat Bahaya Erosi paling kecil terdapat pada kelas Sangat Ringan dengan luas lahan $2.872,01$ ha atau $7,04 \%$ dari luas wilayah keseluruhan. Sebaran spasial Tingkat Bahaya Erosi (TBE) DAS Deli dapat dilihat pada Gambar 4.

Dari hasil analisa spasial Tingkat Bahaya Erosi menunjukkan bahwa tingkat bahaya erosi kategori sangat berat dan berat dominan terdapat pada wilayah hulu dan tengah dengan penggunaan lahan pertanian lahan kering primer, pertanian lahan kering sekunder, tanah terbuka, dan permukiman sedangkan wilayah hutan, perkebunan, sawah, tambak, htan mangrove, dan badan air umumnya berkategori sedang sampai sangat ringan.

Penggunaan lahan pertanian dan tanah terbuka yang mengalami erosi sangat berat dan berat umumnya terdapat pada wilayah hulu yang mempunyai kelerengan 
Tabel 3. Tingkat Bahaya Erosi DAS Deli

\begin{tabular}{llll}
\hline TBE & Erosi (ton/ha/tahun) & Luas Area & \\
\hline (ha) & Persen-tase (\%) & & 37,04 \\
Sangat Berat & $>480$ & $15.107,82$ & 17,07 \\
Berat & $180-480$ & $6.962,85$ & 21,46 \\
Sedang & $60-180$ & $8.752,77$ & 17,38 \\
Ringan & $15-60$ & $7.090,19$ & 7,04 \\
Sangat Ringan & $<15$ & $2.872,01$ & 100,00 \\
Jumlah & & $40.785,65$ & \\
& Erosi rata-rata 410,72 & & \\
& ton/ha/tahun & & \\
\hline
\end{tabular}

Sumber: Hasil Penelitian, 2016

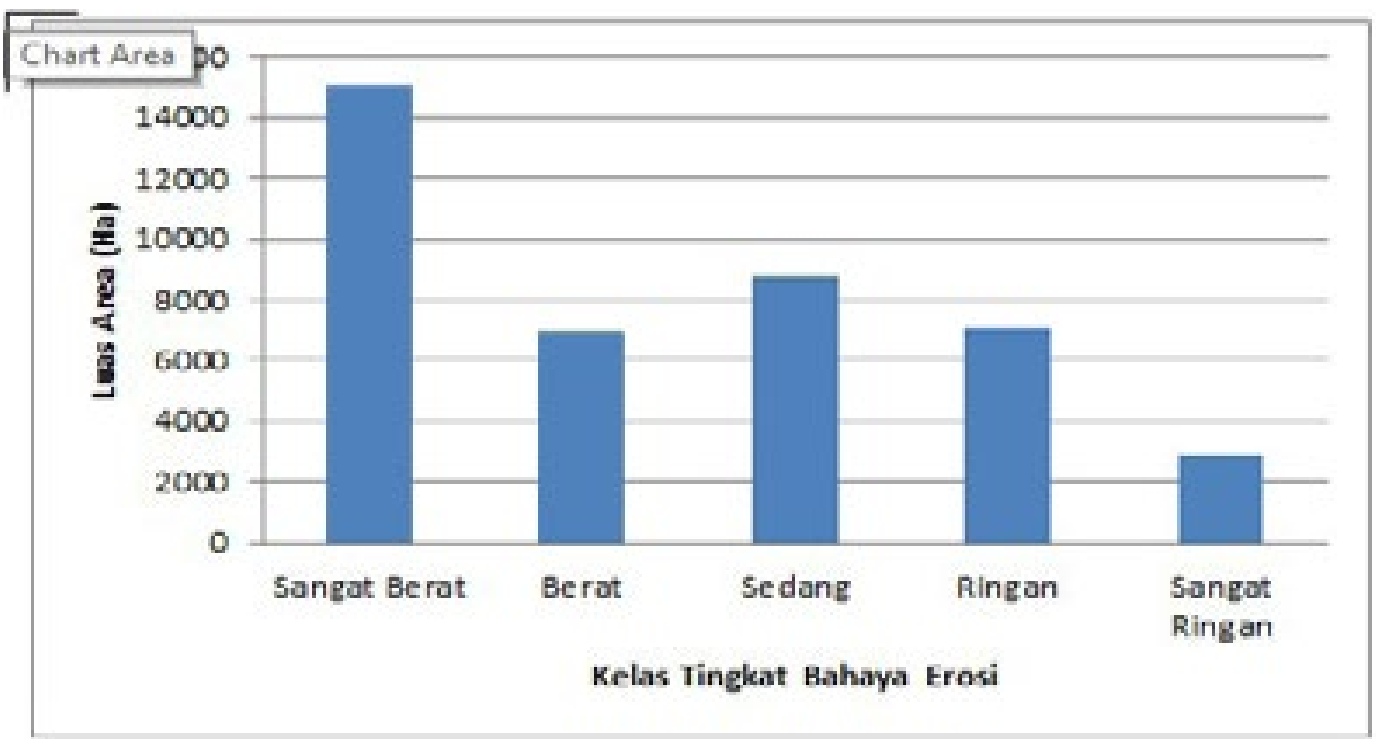

Gambar 5. Tingkat Bahaya Erosi DAS Deli

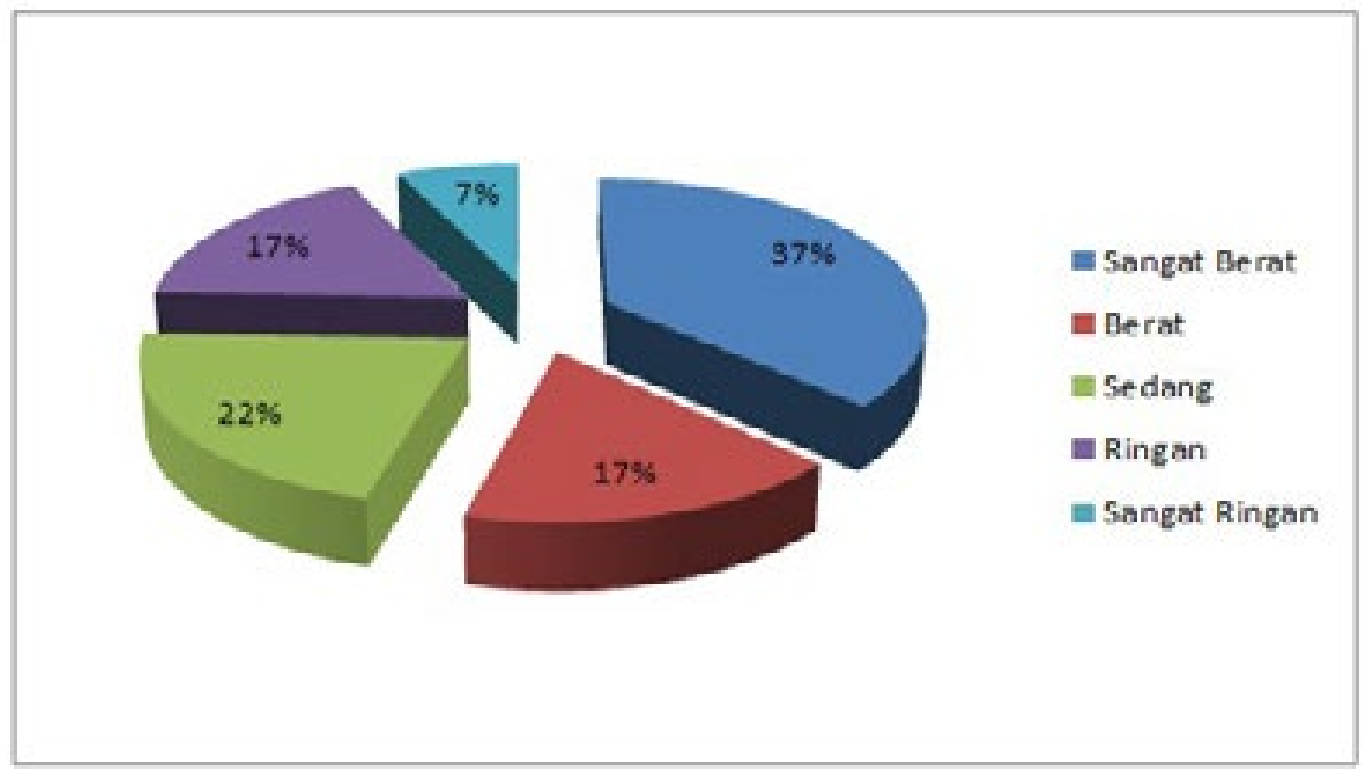

Gambar 6. Persentase Luas Area Masing-masing TBE DAS Deli 


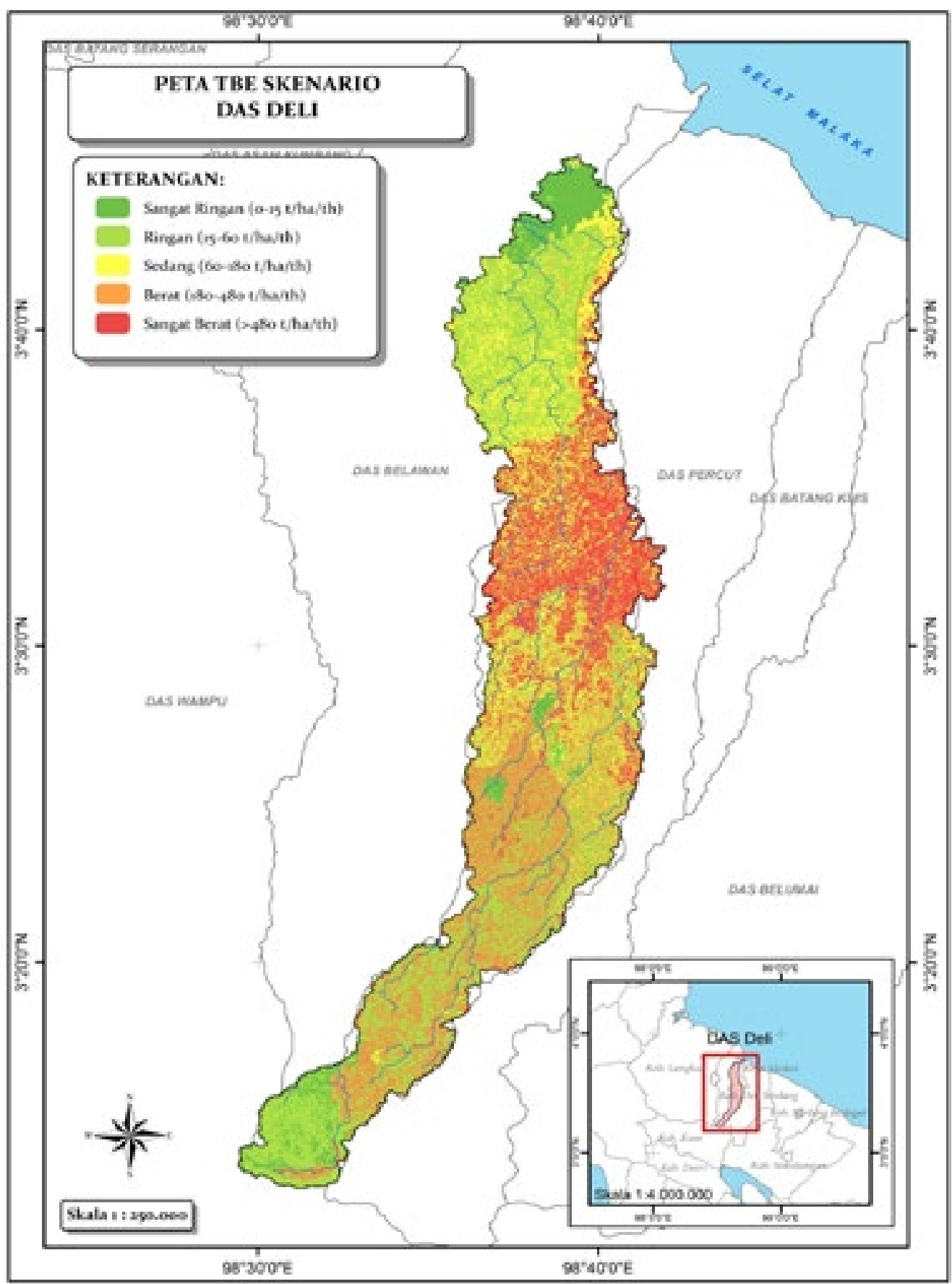

Gambar 7. Peta TBE Skenario DAS Deli

diatas $25 \%$. Hal ini dirasa wajar karena dengan curah hujan yang mencapai $3.000 \mathrm{~mm}$ per tahun ditambah kondisi lereng yang terjal sangat memungkinkan terjadinya erosi dalam jumlah yang besar.

Besarnya tingkat bahaya erosi masing-masing kelas dapat dilihat pada Gambar 5 dan Gambar 6.

\section{Skenario Penggunaan Lahan}

Setelah mendapatkan hasil erosi dan membaginya kedalam tingkat bahaya erosi, langkah selanjutnya adalah skenario penggunaan lahan. Skenario penggunaan lahan dilakukan untuk mendapatkan pola penggunaan lahan yang paling baik dalam menekan laju erosi pada DAS. Dengan melakukan skenario penggunaan lahan diharapkan nilai faktor pengelolaan tanaman (C) pada lahan yang mengalami erosi besar akan menurun sehingga laju erosi di lahan tersebut juga akan turun.

Kegiatan skenario penggunaan lahan ditujukan untuk menentukan pola penggunaan lahan yang paling baik dalam menekan laju erosi pada DAS. Tahapan skenario :

a.Analisa hasil erosi DAS berdasarkan kondisi tataguna lahan eksisting.

b.Melakukan skenario penggunaan lahan yang akan disimulasikan pada model SWAT. Skenario yang dilakukan berdasarkan pada Tingkat Bahaya Erosi 
Tabel 4. Perbandingan TBE Penggunaan Lahan Eksisiting dan Skenario Pada DAS Deli

\begin{tabular}{llllll}
\hline TBE & $\begin{array}{l}\text { Erosi } \\
\text { (Ton/Ha/th) }\end{array}$ & \multicolumn{2}{l}{ Eksisting } & \multicolumn{3}{l}{ skenario } \\
\cline { 3 - 6 } & luas area (ha) & Persentase (\%) & luas area (ha) & Persentase (\%) \\
\hline Sangat Berat & 480 & $15.107,83$ & 37,04 & $5.617,25$ & 13,77 \\
Berat & $180-480$ & $6.962,85$ & 17,07 & $9.519,21$ & 23,34 \\
Sedang & $60-180$ & $8.752,19$ & 21,46 & $8.729,26$ & 21,40 \\
Ringan & $15-60$ & $7.090,19$ & 17,38 & $11.260,40$ & 27,61 \\
Sangat Ringan & 15 & $2.872,01$ & 7,04 & $5.659,54$ & 13,88 \\
Jumlah & & $40.785,65$ & 100 & 40.785 .65 & 100 \\
Erosi Rata-rata & & 410,72 ton/ha/th & 267,88 ton/ha/th \\
\hline
\end{tabular}

Sumber: Hasil Analisis Spasial SIG, 2016

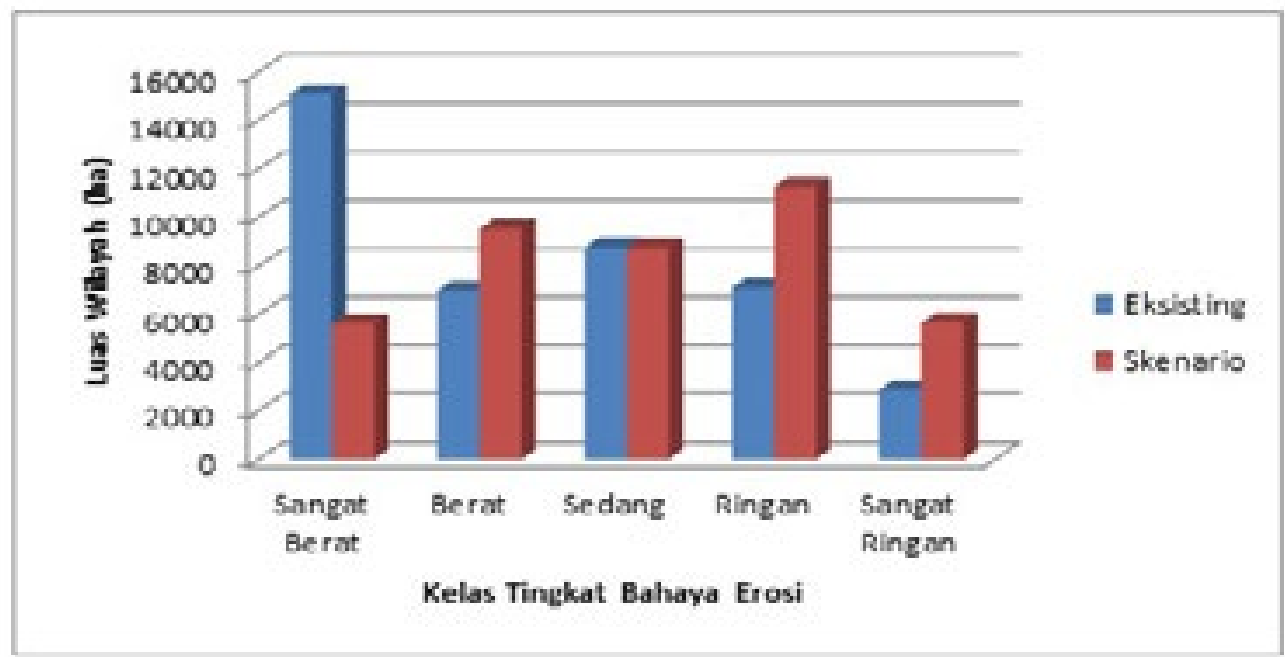

Gambar 8. Perbandingan TBE Penggunaan Lahan Eksisting dan Skenario Pada DAS Deli

(TBE) dan Pola Ruang pada wilayah DAS.

c.Dari hasil skenario yang didapat, maka dilakukan perbandingan dari kondisi tataguna lahan eksisting serta beberapa skenario penggunaan lahan sehingga didapat skenario penggunaan lahan yang paling baik dalam menekan laju erosi DAS.

Penentuan skenario penggunaan lahan pada DAS Deli berpedoman pada analisis besarnya Tingkat Bahaya Erosi (TBE). Adapun langkah-langkah dalam skenario penggunaan lahan pada antara lain:

1.Penggunaan lahan tanah terbuka di daerah hulu DAS dikonversi menjadi hutan lahan kering sekunder dan di daerah tengah dan hilir dikonversi jadi pertanian lahan kering dan perkebunan.

2.Semua penggunaan lahan permukiman yang yang berada di hulu DAS dikonversi menjadi hutan lahan kering primer dan sekunder, sedangkan di daerah tengah dan hilir yang berada di pinggiran dan luar wilayah administrasi Kota Medan dikonversi menjadi perkebunan, pertanian lahan kering, dan tambak.

3.Penggunaan lahan perkebunan yang memiliki TBE kategori sangat berat didaerah hulu diubah menjadi hutan lahan kering sekunder dan didaerah tengah dan hilir dikonversi menjadi pertanian lahan kering.
Setelah dilakukan skenario penggunaan lahan pada DAS Deli, simulasi erosi kembali dijalankan pada model. Besar erosi rata-rata DAS Deli dengan Penggunaan lahan skenario menunjukkan penurunan sebesar $34,78 \%$ dari semula 410,72 ton/ha/tahun menjadi 267,88 ton/ha/tahun. Hasil skenario penggunaan lahan pada DAS Deli dan sebaran spasial TBE dapat dilihat pada Gambar 7 dan Tabel 4.

Dari hasil klasifikasi Tingkat Bahaya Erosi (TBE) penggunaan lahan skenario pada Gambar 7 menunjukkan terjadi penurunan luas besar erosi pada kategori sangat berat yang semula seluas $15.107,83$ ha atau $37,04 \%$ menjadi $5.617,25$ ha atau $13,77 \%$. Untuk TBE kategori berat mengalami kenaikan dari luas $6.962,85$ ha atau $17,07 \%$ bertambah menjadi $9.519,21$ ha atau $23,34 \%$. TBE kategori sedang mengalami sedikit penurunan dari $8.752,77$ ha atau $21,46 \%$ menjadi $8.729,26$ ha atau $21,40 \%$.

Kenaikan signifikan terjadi pada kelas TBE ringan dan sangat ringan, dimana pada TBE ringan terjadi penambahan luas wilayah sebanyak $37,03 \%$ dari yang semula $7.090,19$ ha atau $17,38 \%$ menjadi $11.260,40$ ha atau naik menjadi 27,61\%. Begitu juga dengan TBE sangat ringan yang mengalami kenaikan sebesar 
$49,25 \%$ dari $2.872,01$ ha atau 7,04\% meningkat menjadi $5.659,54$ ha atau $13,88 \%$. Perbandingan TBE eksisting dan skenario dapat dilihat pada Gambar 8.

\section{KESIMPULAN}

Hasil erosi pada DAS Deli menunjukkan besar erosi termasuk kategori berat. Dari hasil validasi pada DAS Deli menunjukkan bahwa keluaran model SWAT tidak berbeda nyata dengan keluaran observasi sehingga model dianggap mampu mensimulasikan erosi dan sedimentasi. Skenario penggunaan lahan DAS Deli dilakukan berdasarkan analisis Tingkat Bahaya Erosi (TBE) DAS. Hasil skenario penggunaan lahan pada DAS Deli menunjukkan terjadi penurunan erosi yang signifikan walaupun masih pada kategori berat.

\section{DAFTAR PUSTAKA}

Arsyad, Sitanala. (2006). Konservasi Tanah dan Air. IPB Press. Bogor.

Asdak, Chay. (2004). Hidrologi dan Pengelolaan Daerah Aliran Sungai. Edisi Revisi. Cetakan ketiga. Gadjah Mada University Presss. Yogyakarta.

Junaidi, Edy. (2013). Peranan Penerapan Agroforestry Terhadap Hasil Air Daerah Aliran Sungai(DAS) Cisadane. Jurnal Penelitian Agroforestry Vol 1 No. 1, Agustus 2013 (Hal 41-53).

Lestari, Moerniti Pudji. (2010). Prdiksi Erosi Menggunakan Metode MUSLE (Studi Kasus: Sub DAS Laban Kab. Boyolali dan DAS Kupang Kab. Pekalongan Jawa Tengah). Tesis. Program Studi Ilmu Kehutanan Program Pascasarjana Fakultas Kehutanan UGM. Yogyakarta.
Miardini, Arina, Totok Gunawan, Sigit Heru Murti. (2016). Kajian Degradasi Lahan Sebagai Dasar Pengendalian Banjir di DAS Juwana. Majalah Geografi indonesia Vol. 30 No 2 September 2016 (134-141).

Mehcram, Siti. (2011). Prediksi Limpasan Permukaan, Erosi, dan Sedimentasi Menggunakan Model AVSWAT2000 (Studi Kasus Di Sub DAS Bengawan SoloHulu). Tesis. Program Studi Teknik Pertanian Fakultas Teknologi PertanianUGM. Yogyakarta.

Nursidah. (2012). Pengembangan Institusi untuk Membangun Kemandirian DalamPengelolaan Daerah Aliran Sungai Terpadu (Studi Kasus Pada Satuan Wilayah Pengelolaan Daerah Sungai Arau Sumatera Barat). Disertasi. Sekolah Pascasarjana IPB. Bogor.

Pandjaitan, Nora. (2015). Analisis Debit Sungai dengan Menggunakan Model SWAT Pada DAS Cipasauran, Banten. JTEP Jurnal Keteknikan Pertanian Vol. 3 No. 2 (Hal 112-130). DOI: 10.19028/jtep.03.2.113120.

Yustika, Rahmah Dewi, Suria Darma Tarigan, Yayat Hidayat, dan Untung Sudadi. (2012). Simulasi Manajemen Lahan di DAS Ciliwung Hulu Menggunakan Model SWAT. Jurnal Informatika Pengairan, Vol. 21 No. 2, Desember 2012 (Hal 7179). 